\title{
Review: treatment with ventilation tubes has little effect in children with otitis media with effusion
}

Rovers MM, Black N, Browning GG, et al. Grommets in otitis media with effusion: an individual patient data meta-analysis. Arch Dis Child 2005;90:480-5.

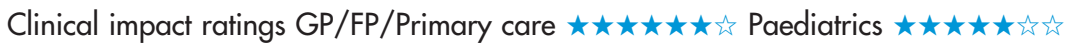

In children with otitis media with effusion (OME), what is the effect of treatment with ventilation tubes and do specific risk groups benefit?

\section{METHODS}

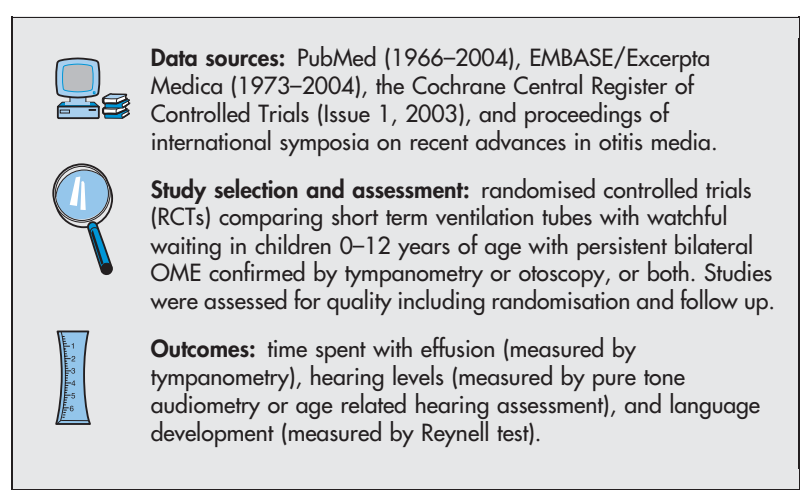

\section{MAIN RESULTS}

10 RCTs met the selection criteria, and 7 trials $(n=1234)$ were included in an individual patient data meta-analysis. Children treated with ventilation tubes had a shorter mean time with effusion at 12 months and a lower mean hearing level at 6 months than those who were in a watchful waiting group (table). Children treated with ventilation tubes and those in a watchful waiting group did not differ for mean hearing levels at 12 months or mean language development at 6-9 months (table). Daycare attendance and baseline hearing level modified the effect of treatment on hearing at 6 months.

\section{CONCLUSION}

In children with otitis media with effusion, the effects of treatment with ventilation tubes compared with watchful waiting are short term and small, with limited evidence of benefit to specific risk groups.

For correspondence: Dr $M$ M Rovers, University Medical Center Utrecht, The Netherlands.mrovers@umcutrecht.nl

Source of funding: Dutch Health Care Insurance Board.

\section{Commentary}

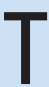
o ventilate or not - that is the question. By age 4 years, OME has affected $80 \%$ of children. OME results in conductive hearing loss associated with fluid in the middle ear. The insertion of ventilation tubes with the aim of improving hearing and speech development is the commonest surgery in children-but does it work? Evidence from RCTs is not encouraging, with only short term benefits in hearing and speech development. ${ }^{1}$ However, the possibility that certain subgroups (eg, those with greater baseline hearing loss) might achieve greater benefits led Rovers et al to revisit the subject.

They performed a meta-analysis using original patient data from published RCTS obtained through collaboration with the original investigators. Of the 1234 children with persistent OME in 7 RCTS, 801 children (4 RCTS) had both ears treated, and 433 (3 RCTS) had only 1 ear treated.

Detailed subgroup analysis found that bilateral ventilation tubes were differentially effective in improving hearing only in young children attending day care. In studies randomising 1 ear to ventilation tubes, subgroup analysis showed a large effect on hearing $(>7 \mathrm{db}$ hearing level at $12 \mathrm{mo}$ ) in those children with baseline hearing losses $>25 \mathrm{~dB}$ hearing level. Rovers et al concluded that ventilation tubes produce small improvements related to continued ventilation-tube presence and patency. Children $\leqslant 3$ years of age attending day care or $\geqslant 4$ years of age with hearing loss $>25 \mathrm{~dB}$ for $>3$ months seemed to benefit more. Otherwise, against both expectation and usual guidance, those with greater hearing impairment did not show significantly more improvement. There were too few participants in high risk subgroups (eg, children with cleft palate or learning problems) for meaningful analysis. So, at present, the evidence favours watchful waiting for normal children with persistent OME - at least until larger RCTs with adequate numbers of high risk children become available.

James Y Paton, MD University of Glasgow Glasgow, UK

1 Lous J, Burton MJ, Fielding JU, et al. Grommets (ventilation tubes) for hearing loss associated with otitis media with effusion in children. Cochrane Database Syst Rev 2005;(1):CD001801.

Ventilation tubes (VT) $v$ watchful waiting (WW) in children with otitis media with effusion*

\begin{tabular}{|c|c|c|c|c|}
\hline \multirow[b]{2}{*}{ Outcomes } & \multirow{2}{*}{$\begin{array}{l}\text { Number of trials } \\
\text { (number of patients) }\end{array}$} & \multicolumn{2}{|c|}{ Mean } & \multirow[b]{2}{*}{ Mean difference ( $\mathrm{p}$ value or $95 \% \mathrm{Cl}$ ) } \\
\hline & & VT & WW & \\
\hline Time spent with effusion at 12 months (wk) & $\{4\}+(n=557)$ & 20 & 37 & $17(p<0.001)$ \\
\hline Binaural hearing level at 6 months $(\mathrm{dB})$ & $4(n=381)$ & 26.6 & 31.1 & 4.5 (1.7 to 7.3$)$ \\
\hline Binaural hearing level at 12 months $(\mathrm{dB})$ & $4(n=379)$ & 27.3 & 27.6 & $0.3(-2.7$ to 2.1$) \S$ \\
\hline $\begin{array}{l}\text { Language development at 6-9 months } \\
\text { (standardised z score) }\end{array}$ & $3(n=381)$ & 0.02 & -0.003 & $0.02(-2.8$ to 2.8$) \S$ \\
\hline
\end{tabular}

${ }^{*} \mathrm{Cl}=$ confidence interval; $\mathrm{SE}=$ standard error

†Data provided by author.

§Not significant. 